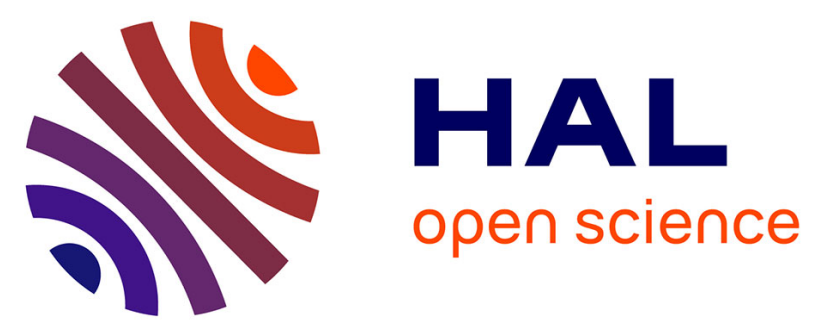

\title{
Influence of Fluorene and Spirobifluorene Regioisomerism on the Structure, Organization, and Permeation Properties of Monolayers
}

Joanna Jalkh, Sébastien Thiery, Jean-François Bergamini, Philippe Hapiot, Cyril Poriel, Yann Leroux

\section{To cite this version:}

Joanna Jalkh, Sébastien Thiery, Jean-François Bergamini, Philippe Hapiot, Cyril Poriel, et al.. Influence of Fluorene and Spirobifluorene Regioisomerism on the Structure, Organization, and Permeation Properties of Monolayers. Journal of Physical Chemistry C, 2017, 121 (26), pp.14228-14237. 10.1021/acs.jpcc.7b04193 . hal-01578523

HAL Id: hal-01578523

https://hal-univ-rennes1.archives-ouvertes.fr/hal-01578523

Submitted on 29 Aug 2017

HAL is a multi-disciplinary open access archive for the deposit and dissemination of scientific research documents, whether they are published or not. The documents may come from teaching and research institutions in France or abroad, or from public or private research centers.
L'archive ouverte pluridisciplinaire HAL, est destinée au dépôt et à la diffusion de documents scientifiques de niveau recherche, publiés ou non, émanant des établissements d'enseignement et de recherche français ou étrangers, des laboratoires publics ou privés. 


\title{
Influence of Fluorene and Spirobifluorene
}

\section{Regioisomerim on the Structure, Organization and}

\section{Permeation Properties of Monolayers}

\author{
Joanna Jalkh, Sébastien Thiery, Jean-François Bergamini, Philippe Hapiot, Cyril Poriel, Yann \\ R. Leroux*
}

Université de Rennes 1, Institut des Sciences Chimiques de Rennes (Equipe MaCSE), CNRS, UMR 6226, Campus de Beaulieu, Bat 10C, 35042 Rennes Cedex, France.

\begin{abstract}
.
9,9'-Spirobifluorene (SBF) and Fluorene derivatives are extensively used as active layer in many organic electronic devices nowadays, thus careful examination of their structure and organization in thin films and monolayers are of primary importance. In the present work, immobilization of SBF and Fluorene isomers was performed via Click Chemistry coupling reaction onto wellordered ethynylbenzene monolayers on carbon substrates. Characterization of the as-prepared monolayers was performed by classical electrochemical techniques (CV), Scanning Electrochemical Microscopy (SECM) and Atomic Force Microscopy (AFM) highlighting the effect of SBF and Fluorene onto the structure and organization of the obtained monolayers. The
\end{abstract}


significant impact of their positional isomerism on the monolayers structuration was clearly evidenced. Indeed, 2-substituted SBF and Fluorene monolayers appear to be more compact and ordered than their 4-substituted analogues, and are orientated parallel to the surface. These findings should have an important impact on the construction and performances of SBF and Fluorene based organic electronic devices. 


\section{Introduction}

The discovery of the 'spiro-concept' which is constituted by the orthogonal junction of two fluorenyl cores via a spiro carbon was introduced in the nineties by Salbeck et al., 9,9'spirobifluorene (SBF). This concept has become a central scaffold in the emergent technologies of organic electronics. ${ }^{1,2}$ Indeed, due to the perpendicular arrangement of the $\pi$-systems, the SBF structure displays many appealing properties such as high thermal/morphological and emission color stability, which are key properties for Organic Light-Emitting Diodes (OLED) applications. $^{1,2,3,4}$ The SBF fragment also presents a considerable interest in the design of solar cells as it is the central core of the famous hole transport material 2,2',7,7'-Tetrakis[N,N-di(4methoxyphenyl)amino]-9,9'-spirobifluorene (Spiro-OMeTAD). ${ }^{5,6}$ Due to its particular geometry, the SBF fragment is not only restricted to electronic applications and has also been successfully used in other applications such as chiral ligand,,$^{7,8,9,10}$ homogeneous ${ }^{11,12}$ and heterogeneous ${ }^{12,13}$ catalysts or as building unit in coordination polymers, ${ }^{14,15,16}$ clearly showing all the versatility of this fragment.

Thus, in the emerging technology of molecular electronics, immobilization of SBF-based materials on surface is also an important feature, which has been demonstrated by means of electro-polymerization techniques, ${ }^{12,17}$ sublimation $^{3}$ or spin-coating process. ${ }^{18}$ These techniques offer a convenient way to immobilize SBF onto surfaces but lead to disordered multilayer films. To our knowledge, only one example in the literature describes the immobilization of SBF-based molecules into an ordered monolayer. ${ }^{19}$ This was accomplished by post-functionalization of a Self-Assembled Monolayers (SAMs) of acid-terminated alkanethiols on gold, forming either chemically bonded or physisorbed films. Even if SAMs are known from decades and allow the 
preparation of well-ordered and compact monolayer films, this approach could only be applied to few materials and mainly coinage metals.

Considering the practical applications, the use of coinage metals has to be limited or even suppressed due to their cost and limited supply. Since its discovery in the beginning of the nineties, ${ }^{20}$ the use of (electro) reduction of aryl diazonium salts becomes a more and more popular technique that tends nowadays to compete with SAMs as an efficient surface functionalization method. Compare to SAMs, this technique can be performed on a wider range of materials (conducting, semiconducting or insulating surfaces) including carbon, yields highly robust interfaces (involving covalent bonds in the case of carbon surfaces) which are in a frozen configuration and is fast (minutes compare to hours or even days for SAMs). ${ }^{21}$ The major drawback of the technique is the difficult controls of the reaction extend that generally leads to disordered multilayer films. This is due to the high reactivity of aryl radicals generated during the electrografting process. Since 2007, new methods have been developed for obtaining (sub) monolayer films via the (electro) reduction of aryl diazonium cations. ${ }^{22,23,24,25}$ Robust, postfunctionalized ordered monolayer films can now be easily obtained onto carbon surfaces using a protection - deprotection strategy. ${ }^{26}$ The density of immobilized molecules could be finely tuned by carefully choosing the protecting groups used during the electro-grafting process. ${ }^{27}$ After deprotection step, it leaves nanometric pinholes in the monolayer whose size is directly related to the steric hindrance of the protecting group that was removed. These monolayers can be then post-functionalized by a Huisgen 1,3-dipolar cycloaddition ${ }^{28,29}$ also known as "Click Chemistry", allowing the immobilization of a wide range of molecules and functional groups. 
In this work, we have examined the preparation and characterization of SBF monolayers covalently bonded onto carbon substrates via the protection - deprotection strategy. Herein, the density of immobilized SBF-based molecules is controlled by the underneath monolayer. In order to evaluate the influence of the molecular arrangement onto the physico-chemical properties of the as-prepared monolayer, two different SBF positional isomers substituted either at $\mathrm{C} 2$ or at $\mathrm{C} 4$ were immobilized. Due to the specific perpendicular arrangement and bulkiness of SBF molecules, we were particularly interested in studying the molecular packing (compactness) of the as-prepared monolayers. In order to highlight the influence of the spiro connected fluorene present in SBF isomers, 2-substituted and 4-substituted fluorene analogues were also immobilized in identical conditions. Characterization of the 2-substituted and 4-substituted SBF and fluorene monolayers were studied by classical electrochemical techniques, Scanning Electrochemical Microscopy and atomic force microscopy. This work not only reports the covalent immobilization of SBF monolayers onto carbon materials, but also shed light on the influence of positional isomerism ( 2 2 vs $\mathrm{C} 4)$ on the monolayers organization and electrochemical properties. 


\section{Experimental methods}

Chemicals. Unless specified, all compounds were commercially available reagents and were used as received. Tetrabutylammonium hexafluorophosphate $\left(n \mathrm{Bu}_{4} \mathrm{NPF}_{6}\right)$ of electrochemical grade and 2-bromofluorene (2-Br-F) was purchased from Aldrich. 4-((triisopropylsilyl)ethynyl) benzenediazonium tetrafluoroborate (TIPS-Eth- $\mathrm{ArN}_{2}{ }^{+}$), ${ }^{30}$ 4-azidomethylphenylboronic acid, ${ }^{31} 4$ bromofluorene (4-Br-F), ${ }^{32}$ 2-bromo-9,9'-spirobi[fluorene] (2-Br-SBF), ${ }^{33}$ 4-bromo-9,9'spirobi[fluorene] (4-Br-SBF) ${ }^{34}$ was prepared according to previously described procedures. The synthesis of the azido derivatives was realized by Suzuki cross coupling reaction between 4azidomethylphenylboronic acid and the respective bromo derivatives (fluorene or Spirobifluorene).

\section{General procedure for Suzuki cross-coupling reaction:}

Bromo derivative (1 eq), (4-azidomethyl)boronic acid (1.5 eq), potassium carbonate (1 eq) and palladium tetrakistriphenylphosphine $(5 \mathrm{~mol} \%)$ were added in a schlenk tube under an argon atmosphere. THF $(30 \mathrm{~mL})$ and water $(6 \mathrm{~mL})$ were added and the solution was degased for $5 \mathrm{~min}$ prior to heating at $70^{\circ} \mathrm{C}$ overnight. After cooling, the reaction mixture was quenched with brine $(30 \mathrm{~mL})$ and extracted with dichloromethane $(3 \times 30 \mathrm{~mL})$. The combined extracts were dried $\left(\mathrm{MgSO}_{4}\right)$ and the solvent was removed in vacuo and purified by column chromatography on silica (see specific elution conditions in each part below)

2-Azidomethylphenyl-9,9'-spirobi[fluorene] (2-SBF-Ph-CH $\left.\mathbf{C H}_{2}-\boldsymbol{N}_{3}\right)$ : 2-Azidomethylphenyl-9,9'spirobi[fluorene] was synthesized according the general cross-coupling procedure starting from 2-Br-SBF ${ }^{33}$ (50 mg, $0.13 \mathrm{mmol}$ ). Silica gel column chromatography was performed using a 


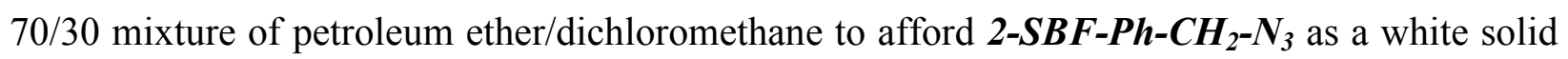
(53 mg); Yield $=94 \% .{ }^{1} \mathrm{H}$ NMR (300 MHz) in $\mathrm{CDCl}_{3}: \delta 4.40 \mathrm{ppm}(\mathrm{s}, 2 \mathrm{H}), \delta 6.65 \mathrm{ppm}(\mathrm{m}, 1 \mathrm{H})$, $\delta 6.70 \mathrm{ppm}(\mathrm{m}, 2 \mathrm{H}), \delta 6.86 \mathrm{ppm}(\mathrm{dd}, \mathrm{J}=1.7,0.6 \mathrm{~Hz}, 1 \mathrm{H}), \delta 6.92 \mathrm{ppm}(\mathrm{m}, 1 \mathrm{H}), \delta 7.01 \mathrm{ppm}(\mathrm{d}, \mathrm{J}$ $=1.2,1 \mathrm{H}), \delta 7.03 \mathrm{ppm}(\mathrm{d}, \mathrm{J}=1.2 \mathrm{~Hz}, 1 \mathrm{H}), \delta 7.06 \mathrm{ppm}(\mathrm{d}, \mathrm{J}=1.2 \mathrm{~Hz}, 1 \mathrm{H}), \delta 7.27 \mathrm{ppm}(\mathrm{t}, \mathrm{J}=1.1$ $\mathrm{Hz}, 1 \mathrm{H}), \delta 7.29 \mathrm{ppm}(\mathrm{t}, \mathrm{J}=1.1 \mathrm{~Hz}, 2 \mathrm{H}), \delta 7.32 \mathrm{ppm}(\mathrm{t}, \mathrm{J}=1.1 \mathrm{~Hz}, 1 \mathrm{H}), \delta 7.35 \mathrm{ppm}(\mathrm{m}, 2 \mathrm{H}), \delta$ $7.53 \mathrm{ppm}(\mathrm{dd}, \mathrm{J}=8.0,1.73 \mathrm{~Hz}, 1 \mathrm{H}), \delta 7.78 \mathrm{ppm}(\mathrm{m}, 2 \mathrm{H}), \delta 7.79 \mathrm{ppm}(\mathrm{m}, 1 \mathrm{H}), \delta 7.83 \mathrm{ppm}(\mathrm{dd}, \mathrm{J}$ $=7.9,0.65 \mathrm{~Hz}, 1 \mathrm{H})$.

4-Azidomethylphenyl-9,9'-spirobi[fluorene] (4-SBF-Ph-CH$-\boldsymbol{H}_{2}-\boldsymbol{N}_{3}$ ) : 4-Azidomethylphenyl-9,9'spirobi[fluorene] was synthesized according general coupling protocol starting from 4-Br-SBF ${ }^{34}$ (50 mg, $0.13 \mathrm{mmol}$ ). Silica gel column chromatography was performed using a 1/1 mixture of petroleum ether/dichloromethane to afford 4-SBF-Ph-CH$-\boldsymbol{H}_{2}-N_{3}$ as a white solid (50 mg); Yield = 88\%. ${ }^{1} \mathrm{H}$ NMR $(300 \mathrm{MHz})$ in $\mathrm{CDCl}_{3}: \delta 4.40 \mathrm{ppm}(\mathrm{s}, 2 \mathrm{H}), \delta 6.71 \mathrm{ppm}(\mathrm{m}, 2 \mathrm{H}), \delta 6.80 \mathrm{ppm}(\mathrm{m}$, 2H), $\delta 7.02 \mathrm{ppm}(\mathrm{m}, 3 \mathrm{H}), \delta 7.15 \mathrm{ppm}(\mathrm{m}, 4 \mathrm{H}), \delta 7.38 \mathrm{ppm}(\mathrm{m}, 2 \mathrm{H}), \delta 7.51 \mathrm{ppm}(\mathrm{m}, 2 \mathrm{H}), \delta 7.65$ $\operatorname{ppm}(\mathrm{m}, 2 \mathrm{H}), \delta 7.86 \mathrm{ppm}(\mathrm{m}, 2 \mathrm{H})$.

2-Azidomethylphenylfluorene $\quad\left(2-\boldsymbol{F}-\mathbf{P h}-\mathrm{CH}_{2}-\boldsymbol{N}_{3}\right): \quad$ 2-Azidomethylphenylfluorene $\quad$ was synthesized according general cross-coupling procedure starting from 2-Br-F (0.15 g, 0.61 mmol). Silica gel column chromatography was performed for purification using a 1:1 mixture of dichloromethane/petroleum ether to afford $\mathbf{2}-\boldsymbol{F}-\boldsymbol{P h}-\boldsymbol{C H}_{2}-\boldsymbol{N}_{3}$ as a white solid $(111 \mathrm{mg})$; Yield = 61\%. ${ }^{1} \mathrm{H}$ NMR (300 MHz) in $\mathrm{CDCl}_{3}: \delta 3.97 \mathrm{ppm}(\mathrm{s}, 2 \mathrm{H}), \delta 4.40 \mathrm{ppm}(\mathrm{s}, 2 \mathrm{H}), \delta 7.32 \mathrm{ppm}(\mathrm{m}$, $1 \mathrm{H}), \delta 7.41 \mathrm{ppm}(\mathrm{m}, 2 \mathrm{H}), \delta 7.42 \mathrm{ppm}(\mathrm{t}, \mathrm{J}=1.1 \mathrm{~Hz}, 1 \mathrm{H}), \delta 7.55 \mathrm{ppm}(\mathrm{m}, 1 \mathrm{H}), \delta 7.60 \mathrm{ppm}(\mathrm{m}$, $1 \mathrm{H}), \delta 7.70 \mathrm{ppm}(\mathrm{m}, 2 \mathrm{H}), \delta 7.78 \mathrm{ppm}(\mathrm{m}, 1 \mathrm{H}), \delta 7.82 \mathrm{ppm}(\mathrm{m}, 1 \mathrm{H}), \delta 7.86 \mathrm{ppm}(\mathrm{m}, 1 \mathrm{H})$. 


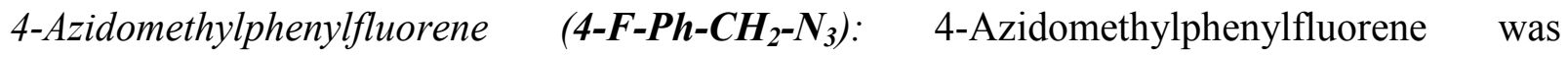
synthesized according general cross-coupling procedure starting from $\mathbf{4}-\mathbf{B r}-\mathbf{F}^{32}(31.8 \mathrm{mg}, 0.13$ mmol). Silica gel column chromatography was performed for purification using a 9:1 mixture of

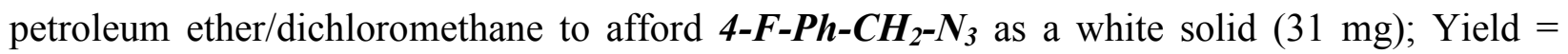
81\%. ${ }^{1} \mathrm{H}$ NMR (300 MHz) in $\mathrm{CDCl}_{3}: \delta 3.88 \mathrm{ppm}(\mathrm{s}, 2 \mathrm{H}), \delta 4.40 \mathrm{ppm}(\mathrm{s}, 2 \mathrm{H}), \delta 6.83 \mathrm{ppm}(\mathrm{m}$, 1H), $\delta 6.98 \mathrm{ppm}(\mathrm{m}, 1 \mathrm{H}), \delta 7.14 \mathrm{ppm}(\mathrm{m}, 3 \mathrm{H}), \delta 7.25 \mathrm{ppm}(\mathrm{m}, 1 \mathrm{H}), \delta 7.42 \mathrm{ppm}(\mathrm{m}, 5 \mathrm{H})$.
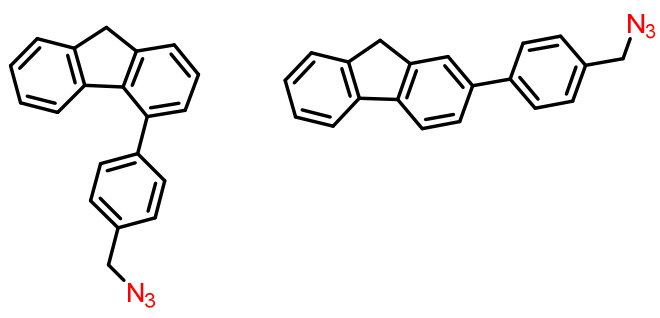

4-F-Ph-CH $-\mathrm{N}_{3}$

2-F-Ph- $\mathrm{CH}_{2}-\mathrm{N}_{3}$
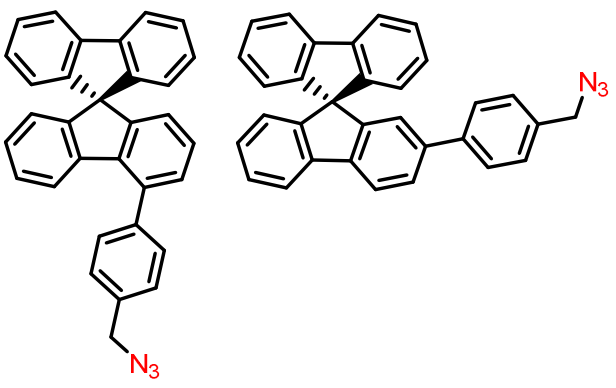

4-SBF-Ph- $\mathrm{CH}_{2}-\mathrm{N}_{3}$

2-SBF-Ph- $\mathrm{CH}_{2}-\mathrm{N}_{3}$

Scheme 1. Molecular structures of the molecules investigated in this work: 4azidomethylphenylfluorene (4-F-Ph- $\mathbf{C H}_{2}-\mathbf{N}_{3}$ ), 2-azidomethylphenylfluorene (2-F-Ph-CH$-\mathbf{H}_{3}$ ), 4-azidomethylphenyl-9,9'-spirobifluorene (4-SBF-Ph-CH$\left.-\boldsymbol{H}_{2}-N_{3}\right)$ and 2-azidomethylphenyl-9,9'spirobifluorene (2-SBF-Ph-CH$\left.-\mathrm{H}_{2}\right)$.

Electrochemical measurements. All electrochemical measurements were performed with an Autolab PGSTAT 12 (Metrohm) and a conventional three-electrode system, comprising the modified substrate as working electrode, a platinum wire as the auxiliary electrode, and SCE electrode (Metrohm) as reference unless otherwise indicated. The glassy carbon electrodes were purchased from $\mathrm{CH}$ Instrument, Inc. (Tx, USA) as 2-mm-diameter rods. The electrodes were 
polished successively with $1.0,0.3$, and $0.05 \mu \mathrm{m}$ alumina slurry made from dry alumina powder and Milli-Q water on microcloth pads ( $\mathrm{CH}$ Instruments, Inc. Tx, USA). The electrodes were thoroughly rinsed with Milli-Q water, acetone and ethanol. Before derivatization, the electrodes were dried with an argon gas stream. The preparation of pyrolized photoresist film (PPF) followed methods described previously. ${ }^{35}$ The PPF substrates were squares of $15 \mathrm{~mm}^{2}$. Different carbon substrates (glassy carbon (GC) and Pyrolyzed Photoresist Film (PPF)) were considered as carbon substrates for the modification. PPF layers and GC present similar reactivity but PPF is more suitable for AFM experiments because of a low roughness. Dry dichloromethane solution was used for cyclic voltammetry investigations of immobilized monolayers. For dry conditions, $\mathrm{Ag} / \mathrm{AgNO}_{3}$ reference electrode was used. Ferrocene $(\mathrm{Fc})$ was added at the end of these experiments and serves as an internal standard. All potentials are referred to SCE reference electrode that was calibrated at $-0.405 \mathrm{~V}$ vs $\mathrm{Fc} / \mathrm{Fc}^{+}$system.

SECM experiments. SECM measurements were performed using $\mathrm{CHI} 900 \mathrm{~B}$ from $\mathrm{CH}-$ Instruments equipped with an adjustable stage for the tilt angle correction and using a typical three-electrode configuration, with a platinum counter electrode and an $\mathrm{Ag} / \mathrm{AgNO}_{3}$ reference electrode. (The substrate is not electrically connected.) The tip (from IJ Cambria) was a gold disk with an effective $7-\mu \mathrm{m}$-radius and a typical $R G=10$. The applied potential at the tip was chosen at the diffusion plateau of the mediator. For a defined sample, all approach curves are adjusted using the same zero origin. This was achieved by simply changing the solution containing the mediator between experiments without moving the tip. The fittings between experimental and theoretical curves were done following the C. Lefrou's approximations based on the BardMirkin's Formalism, where tips parameters (a and RG) were determined independently from 
approach curves of an insulator sample. ${ }^{36,37,38}$ Analyses provide the dimensionless rate constant $\kappa$ $=\mathrm{k}_{\text {eff }} \mathrm{a} / \mathrm{D}$ where $\mathrm{k}_{\text {eff }}$ is an apparent heterogeneous charge transfer constant between the mediator in solution and the substrate. Mira software, develop by Pr. Gunther Wittstock, was use to analyze and fit experimental curves. ${ }^{39}$ All SECM experiments were performed in the dark, at room temperature and using a typical mediator concentration of $10^{-3} \mathrm{~mol} \mathrm{~L}^{-1}$.

\section{Determination of the Apparent Charge Transfer Rate Constants $k_{e l}$. To obtain a more} quantitative analysis, the global charge transfer process was characterized by the apparent charge transfer rate constants $\mathrm{k}_{\mathrm{el}}$ that is the apparent constant for the reaction between the oxidized (or reduced) mediator and the surface under analysis. ${ }^{36}$ This is an approximate procedure as charge transport (or conductivity) inside the film as the potential of the substrate is not controlled. However, $\mathrm{k}_{\mathrm{el}}$ values could easily be derived from adjustments between the experimental approach curves ( $I_{t}$ versus $\left.L\right)$ and dimensionless theoretical curves assuming irreversible electron transfer kinetics for which semi-empirical solutions have been published. ${ }^{36,37,38}$ Following the Bard-Mirkin formalism, these fittings provide the dimensionless parameter $\kappa=\mathrm{k}_{\mathrm{el}} \mathrm{a} / \mathrm{D}$ (where a is the electrode radius and $\mathrm{D}$ the diffusion coefficient of the redox mediator). Diffusion coefficient was taken equal for charge and neutral species of the mediator. The diffusion coefficient of dopamine was measured to be equal to $9.3 \times 10^{-6} \mathrm{~cm}^{2} \mathrm{~s}^{-1} \cdot 40$

Electrode modification. The electrochemical procedure used for the modification of the carbon electrodes (GC or PPF substrates) is presented in Scheme 2 and is based on the method described in reference [26]. Briefly, the first step consists on the electro-grafting of the protected TIPS-Eth$\mathrm{ArN}_{2}^{+}$onto carbon electrode from an acetonitrile solution containing $10^{-2} \mathrm{~mol} \mathrm{~L}^{-1}$ TIPS-Eth- 
$\mathrm{ArN}_{2}{ }^{+}$and $10^{-1} \mathrm{~mol} \mathrm{~L}^{-1} n \mathrm{Bu}_{4} \mathrm{NPF}_{6}$ and using 5 cycles between +0.6 and $-0.75 \mathrm{~V}$ (vs SCE) at a scan rate of $50 \mathrm{mV} \mathrm{s}^{-1}$. After rinsing the modified electrodes with acetone and stirring them for $20 \mathrm{~min}$ in $\mathrm{THF}$, deprotection of the silyl group was achieved by immersing the modified electrodes in a stirred THF solution containing $0.1 \mathrm{M} \mathrm{nBu} \mathrm{BF}_{4} \mathrm{NF}$ (tetrabutylammonium fluoride) for 20 min. Post-functionalization of the obtained covalently bonded ethynylbenzene monolayers were performed by a Huisgen 1,3-dipolar cycloaddition (Click Chemistry). The modified electrodes were immersed in a $5 \mathrm{~mL}$ solution of azido terminated SBF or fluorene derivatives (2 $\mathrm{mg}$ ) in THF with $2.5 \mathrm{~mL}$ of a $0.01 \mathrm{~mol} \mathrm{~L}^{-1}$ aqueous solution of $\mathrm{CuSO}_{4} .2 .5 \mathrm{~mL}$ of a $0.02 \mathrm{~mol} \mathrm{~L}^{-1}$ aqueous solution of $\mathrm{L}(+)$-ascorbic acid (containing $80 \mathrm{mg}$ of $\mathrm{NaHCO}_{3}$ ) was added dropwise after degazing the solution for 15 min with argon. The reaction mixture was left stirring for 1 hour. The modified surfaces were cleaned successively in a saturated solution of EDTA, water and acetone. 

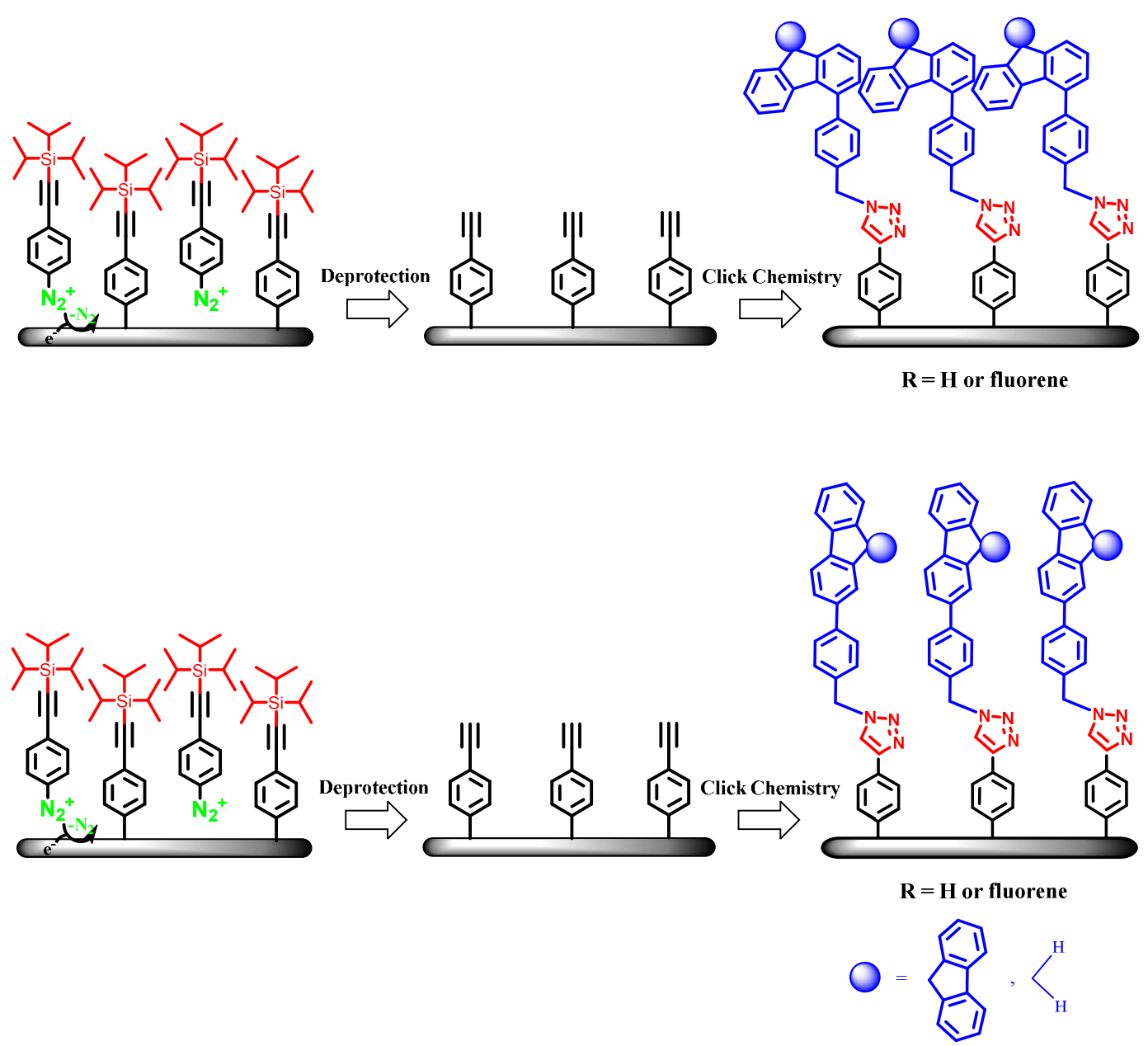

Scheme 2. Schematic representation of the preparation of functionalized carbon surfaces: (i) electro-grafting of TIPS-Eth- $\mathrm{ArN}_{2}{ }^{+}$(ii) deprotection step and (iii) attachment of 2-substituted or 4-susbtituted fluorene and spirobifluorene based derivatives via Click Chemistry.

Atomic Force Microscopy (AFM) experiments. All atomic force microscopy (AFM) experiments have been performed on a NT-MDT Ntegra microscope. Experiments were performed in order to estimate the thickness of the organic layers by the McCreery AFM "scratch" procedure. ${ }^{41}$ The term "AFM scratching" is used here to describe intentional damage to a modification layer on a relatively hard substrate. These experiments were obtained by scanning the surface in contact mode on a $500 \times 500 \mathrm{~nm}$ square with a force setpoint sufficient to remove 
the organic layer without damaging the PPF substrate (this force setpoint was preliminary determined from scratching experiments on a bare PPF surface). Note that careful examination confirmed that scratching of the underlying PPF substrate did not occur. Loose debris from the scratch often created AFM tip-surface tracking problems, but these could be overcome by gentle air convection near the AFM tip to remove most of the debris. After scratching, the surfaces were imaged in semi-contact mode and the images were treated by Gwyddion open-source software. ${ }^{42}$ The heights of organic layers were extracted from the depths of the scratched zones averaged on different profiles.

Modelization. The conformation of the immobilized molecules was optimized using DFT calculations at the B3LYP/6-31G* level. All calculations were performed using the Gaussian 03 package with the default parameters. ${ }^{43}$ 


\section{Results and discussions}

3.1. Preparation and electrochemical investigations of SBF and fluorene monolayers

Immobilization of SBF and fluorene based molecules on carbon surfaces were performed using the protection - deprotection strategy as shown in Scheme 2. Briefly, it first consists in the electro-reduction of an ethynylbenzene diazonium salts protected by a tri(isopropyl)silyl group (labelled TIPS-Eth-Ar- $\mathrm{N}_{2}^{+}$below). The TIPS group has herein a dual role. It hides the alkynil hydrogen atom hence avoiding unwanted side reactions, but also has a structuration role due to its bulkiness avoiding the formation of multilayers. Deprotection of TIPS groups is then performed by immersing the modified electrodes in a THF solution containing tetrabutylammonium fluoride $\left(n \mathrm{Bu}_{4} \mathrm{NF}\right)$ as deprotecting agent, leading to an ethynylbenzene monolayer onto the carbon substrates. In order to be able to immobilized SBF and fluorene derivatives by Click Chemistry onto these monolayers, 4-azidomethylphenylfluorene (4-F-Ph$\left.\mathbf{C H}_{2}-\mathbf{N}_{3}\right), \quad$ 2-azidomethylphenylfluorene $\quad\left(\mathbf{2}-\mathbf{F}-\mathbf{P h}-\mathbf{C H}_{2}-\mathbf{N}_{3}\right), \quad$ 4-azidomethylphenyl-9,9'spirobifluorene (4-SBF-Ph-CH$-\boldsymbol{H}_{2}-\boldsymbol{N}_{3}$ ) and 2-azidomethylphenyl-9,9'-spirobifluorene (2-SBF-Ph$\left.\mathrm{CH}_{2}-\boldsymbol{N}_{3}\right)$ were synthesized in one step by Suzuki cross-coupling reaction between 4azidomethylphenylboronic acid and the corresponding 2-substituted or 4-substituted bromospirobifluorene or bromofluorene derivatives (see experimental methods).

Classical surface characterization techniques such as X-ray Photoelectron Spectroscopy (XPS) or Infrared Spectroscopy (IR) are not relevant techniques in these experiments as the present monolayers are mainly constituted of $\mathrm{C}$ and $\mathrm{H}$ atoms and immobilized on carbon substrates. However, fluorene and SBF derivatives are also known to be electro-active materials ${ }^{44,45}$ and electrochemical investigations has been proven to be a powerful tool to characterize 
functionalized surfaces. ${ }^{46}$ First, ferrocyanide was chosen as a redox probe in solution to investigate the blocking behavior of the surfaces at each step of their modifications. The redox behavior of ferrocyanide has already been used to probe the formation of ethynylbenzene monolayers on carbon. ${ }^{27}$ Ferrocyanide has an inner sphere character which allows the observation of subtle surface modifications which is an essential feature for the analysis of such monolayers. As shown in Figure 1, after electro-grafting step, the ferrocyanide oxidation is totally inhibited (Figure 1, green curves) probing the compact and pinhole free structure of the monolayers obtained by the electro-reduction of TIPS-Eth-Ar- $\mathrm{N}_{2}^{+}$. After the deprotection of the monolayer (removal of the TIPS group to release the alkynil hydrogen atom), ferrocyanide oxidation current reappears, but displays a larger peak to peak potential separation and a global decrease of the current (Figure 1, blue curves) compare to the bare carbon surfaces (Figure 1, red curves). As the size of the TIPS group is bulkier than the underneath ethynylbenzene monolayer, the deprotection step induces the presence of nanometric pinholes in the monolayer structure. Previous simulations studies, ${ }^{27}$ assuming a model of interacting pinholes, has confirmed that the electrochemical response of ferrocyanide/ferricyanide redox couple is governed by diffusion channels, highlighting that the reappearance of ferrocyanide electrochemical response is dependent on the number and size of nanometric pinholes created during the deprotection step. Immobilization of SBF and fluorene derivatives by Click Chemistry on these nanostructured monolayers will have a strong impact on the electrochemical response of ferrocyanide/ferricyanide redox couple, as it will modulate the number and size of nanometric pinholes, depending on the structure of each immobilized molecule and on their organization on the modified surfaces. Immobilization of 2-SBF-Ph- $\mathbf{C H}-\mathbf{H}_{2}-\mathbf{N}_{\mathbf{3}}$ totally inhibits the oxidation of ferrocyanide in the potential range studied (Figure 1a, black curve). This result first confirms the 
very good immobilization of SBF derivatives by this strategy. It also indicates that immobilization of 2-SBF-Ph- $\mathbf{C H}_{2}-\mathbf{N}_{\mathbf{3}}$ on the monolayer is dense and homogenous, and decreases the size of the nanometric pinholes at least down to the size of the ferrocyanide redox probe (see below). Immobilization of 4-SBF-Ph- $\mathbf{C H}_{2}-\mathbf{N}_{3}$ also inhibits ferrocyanide oxidation. (Figure 1b, black curve) However and oppositely to the above described 2-SBF-Ph- $\mathbf{C H} \mathbf{H}_{\mathbf{2}}-\mathbf{N}_{\mathbf{3}}$, the inhibition is only partial. Thus the immobilization of 4-SBF-Ph-CH $-\mathbf{C H}_{\mathbf{2}}-\mathbf{N}_{\mathbf{3}}$ is efficient but clearly leads to less dense monolayer than their 2-substituted analogues, highlighting the influence of molecular arrangement and hence of regioisomerism on the packing of the obtained monolayer. The same behavior is detected for the immobilization of the two other regioisomers, $\mathbf{2}-\mathbf{F}-\mathbf{P h}-\mathbf{C} \mathbf{H}_{\mathbf{2}}-\mathbf{N}_{\mathbf{3}}$ and 4-F-Ph- $\mathrm{CH}_{2}-\mathbf{N}_{3}$ (Figure 1c and 1d), clearly confirming the influence of the substitution position (C2 vs C4) on the monolayer' organization.

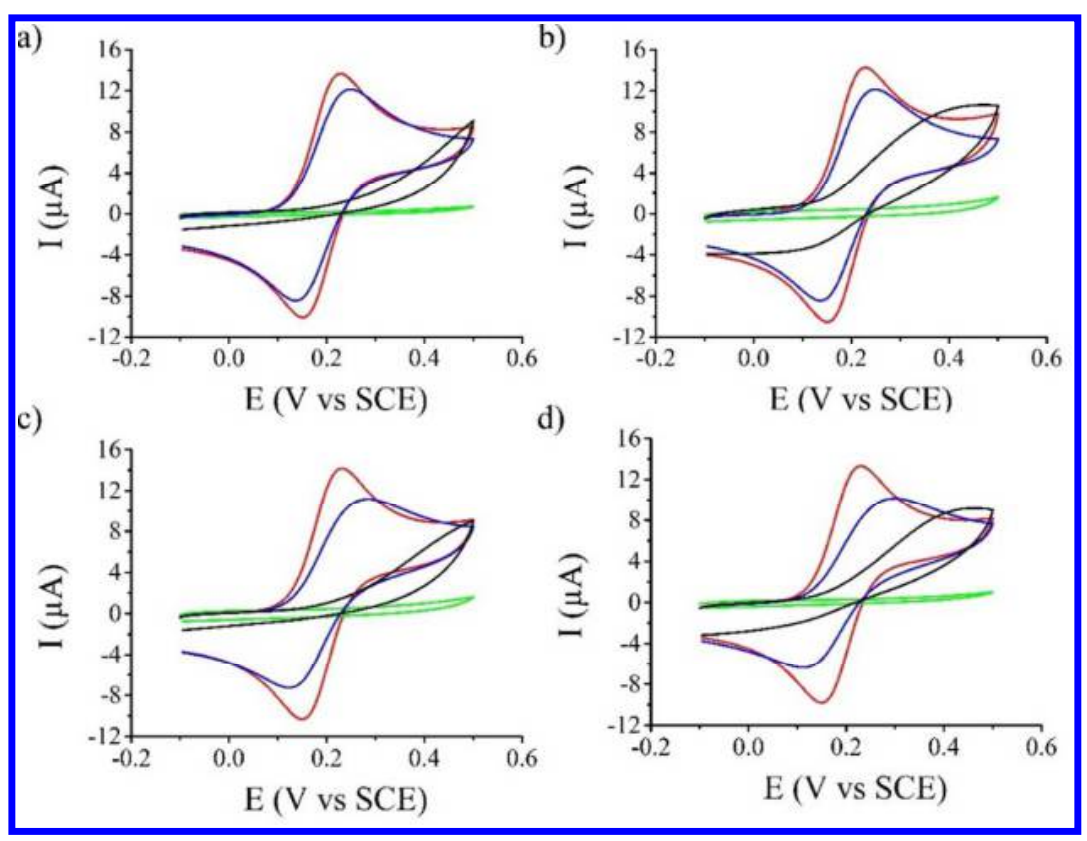

Figure 1. Cycle voltammetry of ferrocyanide $\left(10^{-3} \mathrm{~mol} \mathrm{~L}-1\right)$ in $\mathrm{H}_{2} \mathrm{O}(+0.1 \mathrm{M} \mathrm{KCl})$ at $100 \mathrm{mV} \mathrm{s}^{-1}$ on bare glassy carbon (red curves), on glassy carbon modified by the electro-reduction of TIPSEth-Ar- ${ }_{2}^{+}$before (green curves) and after (blue curves) deprotection with TBAF and modified 
by Click Chemistry (black curves) with (a,c) 2-substituted and (b, d) 4-substituted (a, b) SBF and (c, d) fluorene derivatives.

Scanning Electrochemical Microscopy (SECM) was then used to characterize the modified surfaces. By comparison to previous classical electrochemical techniques, here the sample is analyzed from the solution side. It uses the interaction of an electro-generated probe (redox mediator) that diffuses from a tip electrode to the sample. A typical SECM experiment in feedback mode consists of recording approach curves where the normalized current $I=i / i_{\text {inf }}$ is plotted versus the normalized distance $L=d / a$, in which $i$ is the current at the tip electrode localized at a distance $d$ from the substrate, $i_{i n f}$ is the steady-state current where the tip is an infinite distance from the substrate and $i_{i n f}=4 n F D C a$, with $n$ the number of electrons transferred per species, $F$ the Faraday constant, $D$ the diffusion coefficient, $C$ the initial concentration of the mediator, and $a$ the radius of the UME. ${ }^{47,48}$ The charge transfer properties of the redox mediators toward the modified surfaces could be quantified through the apparent kinetic charge transfer constant $\mathrm{k}_{\mathrm{el}}$, which is obtained from the numerical fitting of the approach curves. Figure $2 \mathrm{a}$ provides a schematic representation of the measurement principle using SECM. Dopamine was chosen as a redox mediator in these experiments as it was shown that the reversible oxidation of dopamine to the corresponding $o$-quinone in aqueous acidic solution is particularly sensitive to surface modification because the molecule needs to reach the substrate to transfer its charge. ${ }^{49}$ Indeed, dopamine has already been demonstrated to be a highly sensitive redox mediator in SECM experiments being able to probe ultrathin layer. ${ }^{50}$ In the present work, the formal redox potential of dopamine $(0.49 \mathrm{~V} v s \mathrm{SCE})^{50}$ is not sufficient to oxidize the immobilized fluorene and 
SBF derivatives. Hence, regeneration of dopamine can only occurs at carbon surfaces via pinholes or defects.

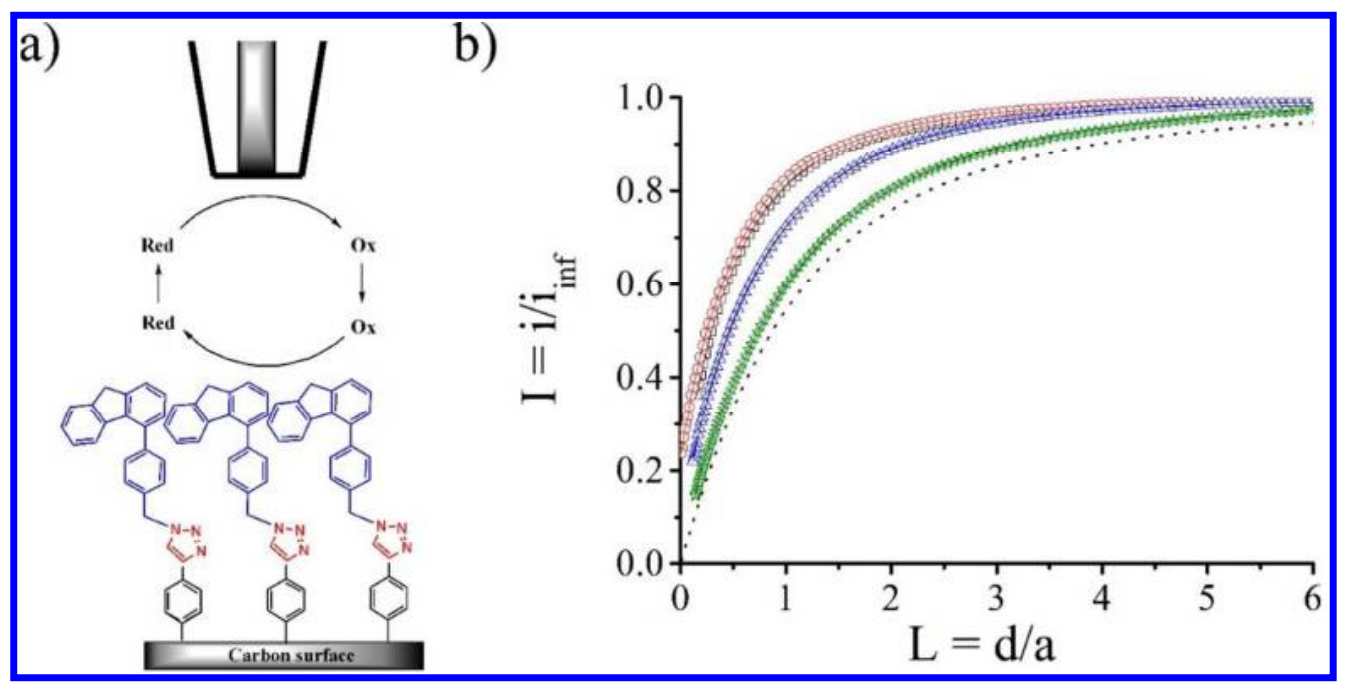

Figure 2. (a) Schematic representation of the SECM measurements on a monolayer (here with the example of the 4-fluorene based monolayer). (b) SECM approach curves using dopamine as redox mediator in an aqueous solution $+0.1 \mathrm{~mol} \mathrm{~L}^{-1} \mathrm{H}_{2} \mathrm{SO}_{4}$ on surfaces modified with 4-F-Ph$\mathrm{CH}_{2}-\mathrm{N}_{3}(\square,-)$, 4-SBF-Ph-CH$-\mathrm{CH}_{3}(\bigcirc,-)$, 2-SBF-Ph-CH$-\mathrm{H}_{3}(\Delta,-)$ and 2-F-Ph-CH$-\mathrm{N}_{3}$ $(\star,-)$. Lines are the fitting curves considering irreversible electron transfer kinetics with the constants reported in Table 1. Black dot curve correspond to totally negative feedback behavior.

As shown in Figure 2b, SECM approach curves performed with dopamine led to negative feedback behavior on all modified surfaces. One could expect to observe a totally negative feedback behavior (Figure 2b, black dot curve) for SECM experiments performed with dopamine as redox mediator on a carbon surface uniformly blocked by a dense and compact organic monolayer. As above mentioned using ferrocyanide as redox probe in solution, monolayers of 2substituted and 4-substituted SBF and fluorene derivatives are defect-free. Therefore, 
regeneration of dopamine in SECM experiments occurs via nanometric pinholes, bringing out a more precise and comparative view of the molecular arrangement of SBF and fluorene monolayer onto carbon substrates. While it was impossible to clearly differentiate the molecular arrangement of 2-subtituted SBF monolayers from that of 2-substituted fluorene ones using ferrocyanide in classical electrochemical experiments, it is clear from SECM experiments that 2substituted fluorene monolayers exhibit a more blocking character than its SBF analogue. Table 1 summarized the apparent kinetic charge transfer constants $\mathrm{k}_{\mathrm{el}}$ of dopamine on each monolayer, giving an indication of the blocking properties of each organic monolayer. 4-Substituted SBF and fluorene monolayers show a similar feedback character with an apparent kinetic charge transfer constant of $\sim 4 \times 10^{-3} \mathrm{~cm} \mathrm{~s}^{-1}$ for both monolayers. Despite the fact that fluorene derivatives have intrinsically lower steric hindrance than their SBF analogues, such similar behaviors in SECM experiments highlight that the structure and organization of the monolayers are imposed by their substitution at $\mathrm{C} 2$ and not by the bulkiness induced by the substitution of the fluorene bridge (i.e. two hydrogen atoms in fluorene vs a spiro-connected fluorene in SBF). This is an interesting finding for further fluorene-based monolayers fabrication. Compare to their 4-substituted analogues, 2-substituted SBF and fluorene monolayers exhibit higher blocking properties as shown by their respective $\mathrm{k}_{\mathrm{el}}$ value in Table 1, which clearly indicates that 2substituted SBF and fluorene monolayers are more dense and compact monolayer than their 4substituted analogues, highlighting again (see above) the influence of the positional isomerism on the monolayer arrangement. 
Table 1. Apparent kinetic charge-transfer constants, $\mathrm{k}_{\mathrm{el}}$, of dopamine redox probe derived from SECM approach curves and surface concentration, $\Gamma$, of immobilized SBF and fluorene derivatives onto ethynylbenzene monolayers.

\begin{tabular}{lclcr} 
& 4-Fluorene & 4-SBF & 2-SBF & 2-Fluorene \\
\hline $\mathrm{K}_{\mathrm{el}}\left(\mathrm{cm} \mathrm{s}^{-1}\right)$ & $4.1 \times 10^{-3}$ & $3.9 \times 10^{-3}$ & $2.2 \times 10^{-3}$ & $3.2 \times 10^{-4}$ \\
$\Gamma \times 10^{-10}\left(\mathrm{~mol} \mathrm{~cm}^{-2}\right)$ & $1.3 \pm 0.4$ & $1.5 \pm 0.3$ & $1.7 \pm 0.3$ & $1.3 \pm 0.1$
\end{tabular}

As above mentioned, fluorene and SBF derivatives are also known to exhibit electrochemical activities. $^{44,45}$ The electrochemical oxidations of 2-phenyl-9,9'-Spirobifluorene (2-Ph-SBF) and 4-phenyl-9,9'-Spirobifluorene (4-Ph-SBF) exhibit two irreversible oxidation peaks at $1.60 \mathrm{~V}$ and 1.93 V vs SCE and $1.66 \mathrm{~V}$ and $1.88 \mathrm{~V}$ vs SCE respectively. ${ }^{33}$ The first peaks are ascribed to the oxidation of the phenyl/fluorene fragments of each molecule. The differences in oxidation potentials between 2-Ph-SBF and 4-Ph-SBF originated from the restricted $\pi$-conjugation of the latter. Indeed, in $\mathbf{2 - P h - S B F}$, thanks to the para linkage between the fluorene and the phenyl fragment, the $\pi$-conjugation pathway is longer than that found in $\mathbf{4 - P h - S B F}$. Indeed, in $\mathbf{4 - P h -}$ SBF, the $\pi$-conjugation is strongly restricted due to the ortho linkage which leads to a sterically hindered environment. ${ }^{32}$ The second oxidation has been attributed to the oxidation of the fluorene. After oxidations, polymeric films deposited on electrode materials exhibit oxidation/reduction wave between $1.0 \mathrm{~V}$ and $2.0 \mathrm{~V}$ vs SCE.

2-Substituted and 4-substituted SBF monolayers were investigated by cyclic voltammetry in similar conditions. As shown in Figure $3 \mathrm{a}$ and $3 \mathrm{~b}$, irreversible oxidation peaks are observed at 1.54 V and 1.60 V vs SCE for 2-substituted and 4-substituted SBF monolayers respectively. These oxidation peaks appears at a similar potential than their phenyl substituted analogues 2Ph-SBF and 4-Ph-SBF in solution. However, no second oxidation peaks are observed for the 
immobilized SBF probably because the second oxidation potential is out of the present electrochemical windows (above $2 \mathrm{~V}$ vs SCE). If so, it should be noted that second oxidation peaks should be separated by more than $400 \mathrm{mV}$ from the first one, when in solution they are separated by a maximum of $330 \mathrm{mV}$. (Figure 3) Such difference in oxidation peak potentials suggests a high constrain of the SBF moieties when they are immobilized in such monolayers. One can note that oxidation peaks disappear if a second scan is recorded, highlighting that all SBF derivatives are oxidized during the first scan (Figure 3, red curves) as expected for a monolayer. On the other hand, no clear electrochemical signal can be attributed to the formation of polymeric films on carbon surfaces on consecutive scans (Figure 3, green curves). The absence of the formation of polymeric films may results from an inappropriate distance between SBF moieties onto the surface. Similar observation can be made on 2-substituted and 4substituted fluorene monolayers. For both monolayers, the only noticeable difference is the presence of an irreversible oxidation peak observed at the same value, around 1.46 V vs SCE. This means that substitution of fluorene derivatives in ortho or para position have no significant effect on the electrochemical behavior of the obtained monolayers. 


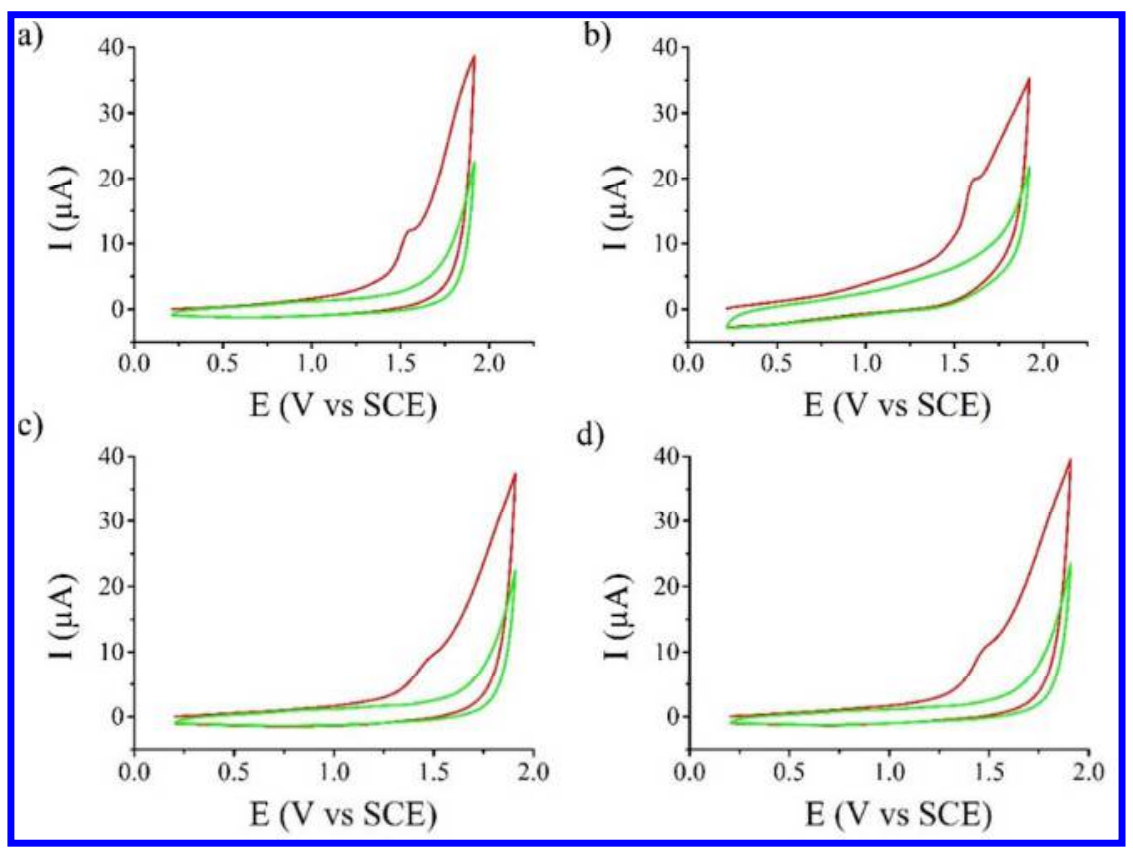

Figure 3. Cycle voltammetry of carbon surfaces modified by (a, c) 2-subtituted and (b, d) 4substituted $(\mathrm{a}, \mathrm{b}) \mathrm{SBF}$ and $(\mathrm{b}, \mathrm{d})$ fluorene monolayers in dry dichloromethane $(+0.2 \mathrm{M}$ $\left.n \mathrm{Bu}_{4} \mathrm{NPF}_{6}\right)$ at $100 \mathrm{mV} \mathrm{s}^{-1}$. Red and green curves corresponding respectively to the first and second scan.

An estimation of the number of SBF and fluorene molecules immobilized onto carbon surfaces could be performed by integration of the electrochemical current of the irreversible oxidation peak. Estimation of the surface concentration, $\Gamma=\mathrm{Q} / \mathrm{nFA}$ (with $\mathrm{n}$ the number of electron exchange by molecules, $\mathrm{F}$ is the faraday number and $\mathrm{A}$ is the geometrical surface of the substrate), of each immobilized molecule are presented in Table 1. We derived an average surface concentration value of $1.5 \pm 0.2 \times 10^{-10} \mathrm{~mol} \mathrm{~cm}^{-2}$ for each molecule. Considering that the maximum number of immobilized molecules is here imposed by the size of the protecting group used during the electrochemical grafting step, which has been calculated to be theoretically $2.3 \mathrm{x}$ $10^{-10} \mathrm{~mol} \mathrm{~cm}{ }^{-2}$ for TIPS group, and the roughness factor of carbon materials, it shows that not all 
ethynylbenzene functional groups have been post-functionalized. This indicates that the steric

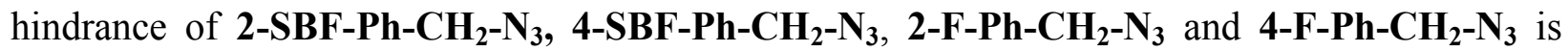
greater than that of the TIPS group and imposes the structure and organization of the as-prepared monolayers.

\subsection{Topological studies of SBF and fluorene monolayers}

Atomic Force Microscopy (AFM) experiments were performed on these monolayers as a complementary technique to characterize the molecular packing and arrangement of the asprepared monolayers. Roughness and thickness of each monolayer are compiled in Table 2. In all case, roughnesses of the monolayers are measured to be less than $5 \AA$ showing the absence of aggregates or large defects. However, whereas 2-substituted SBF and fluorene monolayers exhibit a roughness of $1 \AA$ which is similar to that of the blank PPF substrate, 4-substituted SBF and fluorene monolayers display a high roughness of $4 \AA$. In good agreement with previous SECM experiments, this difference in surface roughness tends to confirm that 4-substituted monolayers are less compact than the 2-substituted ones. Estimation of the thickness of each monolayer was performed using "AFM Scratching" protocol (see experimental section for details). Briefly, in a first step, it consist in scratching the substrate with an AFM tip to detach a small square portion of the organic film without damaging the underneath substrate. Then, AFM picture of the "damage" area is recorded and the thickness of the organic layer can be estimated through line profiles. Example of such experiments is shown in Figure 4, on 2-substituted fluorene monolayers. Experimental measurements of 2-subtituted SBF and fluorene monolayers' thicknesses were found to be similar and close to $6-7 \AA$, whereas 4-substituted SBF and fluorene monolayers' thicknesses are estimated to be $1.9 \mathrm{~nm}$ and $1.2 \mathrm{~nm}$ respectively. 
Table 2. Roughness, experimental and theoretical thickness estimation of 2-substituted and 4substituted SBF and fluorene monolayers measured by AFM experiments and DFT calculations.

\begin{tabular}{llll} 
& \multicolumn{1}{c}{ Roughnes } & Experimental thickness & Theoretical thickness \\
& $\mathrm{S}$ & & \\
Blank PPF & $0.11 \mathrm{~nm}$ & - & - \\
2-fluorene monolayer & $0.10 \mathrm{~nm}$ & $0.75 \pm 0.15 \mathrm{~nm}$ & $1.40 \mathrm{~nm}$ \\
2-SBF monolayer & $0.10 \mathrm{~nm}$ & $0.60 \pm 0.03 \mathrm{~nm}$ & $1.25 \mathrm{~nm}$ \\
4-fluorene monolayer & $0.43 \mathrm{~nm}$ & $1.20 \pm 0.40 \mathrm{~nm}$ & $1.58 \mathrm{~nm}$ \\
4-SBF monolayer & $0.38 \mathrm{~nm}$ & $1.91 \pm 0.18 \mathrm{~nm}$ & $1.70 \mathrm{~nm}$
\end{tabular}

Finally, Density Functional Theory (DFT) calculations were performed in order to evaluate the theoretical thicknesses of these monolayers. As a first approximation, only a single molecule is taken into account here and in gas phase, instead of fixed on a substrate and surrounded by other molecules. Secondly, optimization calculations were performed on SBF and fluorene derivatives link to a benzene ring via a 1,2,3-triazole ring, mimicking the covalent immobilization of these molecules onto the ethynylbenzene monolayers through Click Chemistry coupling reaction. All DFT calculations in these conditions lead to a dihedral angle of $109.3^{\circ}$ between the $1,2,3$-triazole ring and the mean plane of the pendant phenyl ring of SBF or fluorene derivatives (calculated on ADF software ${ }^{51}$ ) due to the presence of the $\mathrm{CH}_{2}$ group between these two fragments. From previous calculations, ${ }^{27}$ the initial ethynybenzene monolayer covalently bonded to the carbon substrate before post-functionalization is estimated to be in a perpendicular arrangement with respect to the substrate. Hence, the main factor influencing the estimated theoretical monolayers' 
thicknesses is the dihedral angle between the mean plane of the pendant phenyl ring and the triazole one. Estimated theoretical thicknesses of each monolayer are presented in Table 2. Comparison of the estimated experimental and theoretical thicknesses should give us information about the orientation of the immobilized molecules with respect to the substrate. Considering that 2-substituted SBF and fluorene monolayers have similar experimental thicknesses of 6-7 $\AA$, which is similar to the thickness of the initial ethtynylbenzene monolayer, the phenyl/triazole dihedral angle should be $90^{\circ}$, i.e. lying parallel to the substrate, instead of the $109.3^{\circ}$. Contrarily, 4-substituted SBF and fluorene monolayers have experimental thickness values higher than the theoretical ones, indicating that these molecules should be linked to the 1,2,3-triazole ring via an angle superior to $109.3^{\circ}$ and can be estimated to be as high as $136^{\circ}$.

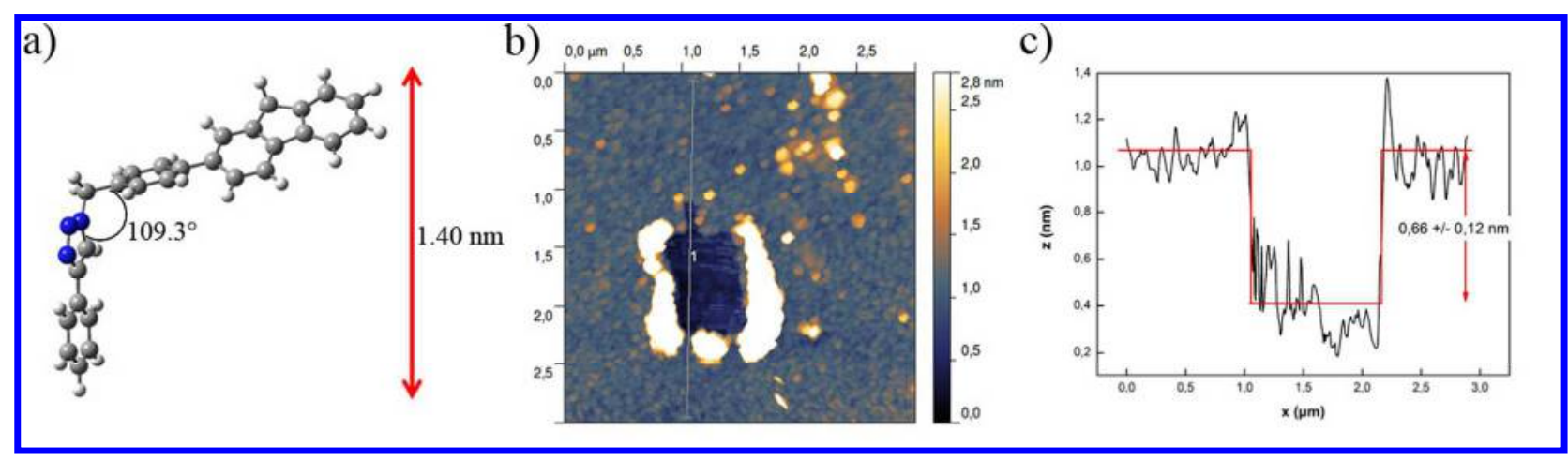

Figure 4. (a) Optimized molecular structures of 2-substituted fluorene derivative attached via a 1,2,3-triazole ring to a benzene ring, mimicking the immobilization onto the surface, using DFT calculations. (b) Topographic picture of PPF substrate modified with 2-substituted fluorene monolayer showing a $0.5 \times 0.5 \mu \mathrm{m}$ scratch. (c) Line profile (black) and adjustment curve (red) of the AFM picture.

4. Conclusion 
Monolayers of 2-substituted and 4-substituted 9,9'-Spirobifluorene (SBF) and Fluorene derivatives were prepared by coupling a protection-deprotection strategy using the electroreduction of a protected aryl diazonium salts and Click Chemistry coupling reaction onto carbon substrates. Electrochemical investigations using redox probes (ferrocyanide and dopamine) in solution show important differences between the permeation properties of the as-prepared monolayers. Monolayers of 2-substituted SBF and Fluorene derivatives are found to be sufficiently compact and organized to totally impede ferrocyanide electro-activity whereas partial ferrocyanide electro-activity is still observable with 4-substituted SBF and Fluorene monolayers evidencing less blocking properties towards molecules in solution. Local electrochemical experiments reveal the presence of nanometric pinholes in all investigated monolayers. However, when the pinholes' number and size seem to be similar for 4-susbtituted SBF and Fluorene monolayers, 2-substituted SBF monolayer exhibits larger pinholes and/or more pinholes than its Fluorene analogue which presents nearly ideal compactness, as it can be expected considering the steric non planar structure of SBF derivatives compare to Fluorene ones. Electro-activities of the studied organic layers are in good agreements with a monolayer arrangement exhibiting an average high surface coverage of $1.5 \pm 0.2 \times 10^{-10} \mathrm{~mol} \mathrm{~cm}^{-2}$. Finally, Atomic Force microscopy (AFM) investigations were in good agreements with previous observations. Comparison between theoretical and experimental layer thicknesses tends to suggest that 2-susbtituted SBF and Fluorene derivatives lie parallel to the substrate whereas 4susbstituted ones are orientated with an angle than can be as high as $46^{\circ}$ from the substrate. Thus, in this work, we report the first comparative study on the immobilization of monolayer of Fluorene and SBF based materials. The strong impact of the regioisomerism has particularly been highlighted and may be used in the future to construct other monolayers. These findings are 
of major interest considering the construction of SBF and Fluorene based organic electronics devices where molecular arrangement has an important impact on the performances of the devices.

1

2

3

4

5

6

7

8

9

10

11

12

13

14

15

16

17

18

19

20

21

22

23

24

25

26

27

28

29

30

31

32

33

34

35

36

37

38

39

40

41

42

43

44

45

46

47

48

49

50

51

52

53

54

55

56

57

58

59

60 


\section{AUTHOR INFORMATION}

Corresponding Author

*Email: yann.leroux@univ-rennes1.fr

Author Contributions

The manuscript was written through contributions of all authors. All authors have given approval to the final version of the manuscript. All authors contributed equally.

\section{ACKNOWLEDGMENT}

J.J. thanks the Région Bretagne for financial support (461-ARED). We wish to thank the ANR HOME-OLED (n¹1-BS07-020-01) for a studentship (ST).

\section{REFERENCES}

(1) Saragi, T. P. I.; Spehr, T.; Siebert, A.; Fuhrmann-Lieker, T.; Salbeck, J. Spiro Compounds for Organic Optoelectronics. Chem.Rev. 2007, 107(4), 1011-1065.

(2) Xie, L.-H.; Liang, J.; Song, J.; Yin, C.-R.; Huang, W. Spirocyclic Aromatic Hydrocarbons (SAHs) and their Synthetic Methodologies. Current Organic Chemistrv 2010, 14, 2169-2195.

(3) Romain, M.; Tondelier, D.; Vanel, J.-C.; Geffroy, B.; Jeannin, O.; Rault-Berthelot, J.; Métivier, R.; Poriel, C. Dependence of the Properties of Dihydroindenofluorene Derivatives on Positional Isomerism: Influence of the Ring Bridging. Angew. Chem.Int. Ed. 2013, 52, 1414714151. 
(4) Poriel, C.; Métivier, R.; Rault-Berthelot, J.; Thirion, D.; Barrière, F.; Jeannin, O. A Robust Pure Hydrocarbon Derivative Based on the (2,1-b)-Indenofluorenyl Core with High Triplet Energy Level. Chem. Commun. 2011, 47, 11703-11705.

(5) Sanchez, R. S.; Mas-Marza, E. Light-Induced Effects on Spiro-OMeTAD Films and Hybrid Lead Halide Perovskite Solar Cells. Solar Energy Materials and Solar Cells 2016, 158, Part 2, 189-194.

(6) Park, N.-G. Perovskite Solar Cells: an Emerging Photovoltaic Technology. Materials Today 2015, 18, 65-72.

(7) Xie, J.-H.; Zhou, Q.-L. Chiral Diphosphine and Monodentate Phosphorus Ligands on a Spiro Scaffold for Transition-Metal-Catalyzed Asymmetric Reactions. Acc. Chem. Res. 2008, 41, $581-593$.

(8) Poriel, C.; Ferrand, Y.; Le Maux, P.; Rault-Berthelot, J.; Simonneaux, G. Electropolymerisation of a New Optically Active Iron Tetraspirobifluorenyl Porphyrin. Synth. Met. 2008, 158, 796-801.

(9) Cheng, X.; Zhang, Q.; Xie, J.-H.; Wang, L.-X.; Zhou, Q.-L. Highly Rigid Diphosphane Ligands with a Large Dihedral Angle Based on a Chiral Spirobifluorene Backbone. Angew. Chem. Int. Ed. 2005, 44, 1118-1121.

(10) Cheng, X.; Zhu, S.-F.; Qiao, X.-C.; Yan, P.-C.; Zhou, Q.-L. A General Synthetic Route to Chiral Dihydroxy-9,9'-Spirobifluorenes. Tetrahedron 2006, 62(34), 8077-8082. 
(11) Poriel, C.; Ferrand, Y.; Le Maux, P.; Rault-Berthelot, J.; Simonneaux, G. Syntheses of Manganese and Iron Tetraspirobifluorene Porphyrins as New Catalysts for Oxidation of Alkenes by Hydrogen Peroxide and Iodosylbenzene. Tetrahedron Lett. 2003, 44, 1759-1761.

(12) Poriel, C.; Ferrand, Y.; Le Maux, P.; Rault-Berthelot, J.; Simonneaux, G. Organic CrossLinked Electropolymers as Supported Oxidation Catalysts: Poly((tetrakis $\left(9,9^{`}-\right.$ spirobifluorenyl)porphyrin)manganese) Films. Inorg. Chem. 2004, 43, 5086-5095.

(13) Poriel, C.; Ferrand, Y.; Juillard, S.; Le Maux, P.; Simonneaux, G. Synthesis and Stereochemical Studies of Di and Tetra 9,9'-Spirobifluorene Porphyrins: New Building Blocks for Catalytic Material. Tetrahedron 2004, 60, 145-158.

(14) Moreau, F.; Audebrand, N.; Poriel, C.; Moizan-Baslé, V.; Ouvry, J. A 9,9’Spirobifluorene Based Metal-Organic Framework: Synthesis, Structure Analysis and Gas Sorption Properties. J. Mater. Chem. 2011, 21, 18715-18722.

(15) Guo, H.-D.; Guo, X. M.; Batten, S. R.; Song, J.-F.; Song, S.-Y.; Dang, S.; Zheng, G.-L.; Tang, J.-K.; Zhang, H.-J. Hydrothermal Synthesis, Structures, and Luminescent Properties of Seven d10 Metal-Organic Frameworks Based on 9,9'-Dipropylfluorene-2,7-Dicarboxylic Acid (H2DFDA). Cryst. Growth Des. 2009, 9, 1394-1401.

(16) Wong, K.-T.; Liao, Y.-L.; Peng, Y.-C.; Wang, C.-C.; Lin, S.-Y.; Yang, C.-H.; Tseng, S.M.; Lee, G.-H.; Peng, S.-M. A Novel Right-Angled Ligand that Forms Polymeric Metal-Organic Frameworks with Nanometer-Sized Square Cavities. Cryst. Growth Des. 2005, 5, 667-674. 
(17) Rault-Berthelot, J.; Granger, M. M.; Mattiello, L. Anodic Oxidation of 9,9'Spirobifluorene in $\mathrm{CH}_{2} \mathrm{Cl}_{2}+0.2 \mathrm{M} \mathrm{Bu} \mathrm{NBF}_{4}$. Electrochemical Behaviour of the Derived Oxidation Product. Synthetic Metals 1998, 97 (3), 211-215.

(18) Tang, S.; Liu, M. R.; Lu, P.; Xia, H.; Li, M.; Xie, Z. Q.; Shen, F. Z.; Gu, C.; Wang, H. P.; Yang, B. et al. A Molecular Glass for Deep-Blue Organic Light-Emitting Diodes Comprising a 9,9'-Spirobifluorene Core and Peripheral Carbazole Groups. Adv. Funct. Mater. 2007, 17, 28692877.

(19) Cecchet, F.; Fioravanti, G.; Marcaccio, M.; Margotti, M.; Mattiello, L.; Paolucci, F.; Rapino, S.; Rudolf, P. Electrode Surface Modification by a Spirobifluorene Derivative. An XPS and Electrochemical Investigation. J. Phys. Chem. B 2005, 109 (39), 18427-18432.

(20) Delamar, M.; Hitmi, R.; Pinson, J.; Saveant, J.-M. Covalent Modification of Carbon Surfaces by Grafting of Functionalized Aryl Radicals Produced from Electrochemical Reduction of Diazonium Salts. J. Am. Chem. Soc. 1992, 114, 5883-5884.

(21) Bélanger, D.; Pinson, J. Electrografting: a Powerful Method for Surface Modification. Chem. Soc. Rev. 2011, 40, 3995-4048.

(22) Nielsen, L. T.; Vase, K. H.; Dong, M.; Besenbacher, F.; Pedersen, S. U.; Daasbjerg, K. Electrochemical Approach for Constructing a Monolayer of Thiophenolates from Grafted Multilayers of Diaryl Disulfides. J. Am. Chem. Soc. 2007, 129, 1888-1889.

(23) Combellas, C.; Kanoufi, F.; Pinson, J.; Podvorica, F. I. Sterically Hindered Diazonium Salts for the Grafting of a Monolayer on Metals. J. Am. Chem. Soc. 2008, 130 (27), 8576-8577. 
(24) Fontaine, O.; Ghilane, J.; Martin, P.; Lacroix, J.-C.; Randriamahazaka, H. Ionic Liquid Viscosity Effects on the Functionalization of Electrode Material through the Electroreduction of Diazonium. Langmuir 2010, 26 (23), 18542-18549.

(25) Menanteau, T.; Levillain, E.; Breton, T. Electrografting via Diazonium Chemistry: From Multilayer to Monolayer Using Radical Scavenger. Chem. Mater. 2013, 25, 2905-2909.

(26) Leroux Y.R.; Hui F.; Noel J.-M.; Roux C.; Hapiot P. Efficient Covalent Modification of a Carbon Surface: Use of a Silyl Protecting Group To Form an Active Monolayer. J. Am. Chem. Soc. 2010, 132 (40), 14039-14041.

(27) Leroux, Y. R.; Hapiot, P. Nanostructured Monolayers on Carbon Substrates Prepared by Electrografting of Protected Aryldiazonium Salts. Chem. Mater. 2013, 25 (3), 489-495.

(28) Rostovtsev, V. V.; Green, L. G.; Fokin, V. V.; Sharpless, K. B. A Stepwise Huisgen Cycloaddition Process: Copper(I)-Catalyzed Regioselective "Ligation" of Azides and Terminal Alkynes. Angew. Chem., Int. Ed. 2002, 41, 2596-2599.

(29) Tornoe, C. W.; Christensen, C.; Meldal, M. Peptidotriazoles on Solid Phase: [1,2,3]Triazoles by Regiospecific Copper(I)-Catalyzed 1,3-Dipolar Cycloadditions of Terminal Alkynes to Azides. J. Org. Chem. 2002, 67, 3057-3064.

(30) Lee, L.; Brooksby, P. A.; Leroux, Y. R.; Hapiot, P.; Downard, A. J. Mixed Monolayer Organic Films via Sequential Electrografting from Aryldiazonium ion and Arylhydrazine Solutions. Langmuir 2013, 29 (9), 3133-3139. 
(31) Fedorov, A. Y.; Shchepalov, A. A.; Bolshakov, A. V.; Shavyrin, A. S.; Kurskii, Y. A.; Finet, J.-P.; Zelentsova, S. V. Synthesis of (Azidomethyl)phenylboronic Acids. Russ. Chem. Bull., Int. Ed. 2004, 53 (2), 370-375.

(32) Sicard, L.; Quinton, C.; Peltier, J.-D.; Tondelier, D.; Geffroy, B.; Biapo, U.; Métivier, R.; Jeannin, O.; Rault-Berthelot, J.; Poriel, C. Spirobifluorene Regioisomerism: A StructureProperty Relationship Study. Chem. Eur. J. 2017, 23, 7719-7727.

(33) Thiery, S.; Declairieux, S.; Tondelier, D.; Seo, G.; Geffroy, B.; Jeannin, O.; Metivier, R.; Rault-Berthelot, J.; Poriel, C. 2-Substituted vs 4-Substituted-9,9'-Spirobifluorene Host Materials for Green and Blue Phosphorescent OLEDs: a Structure-Property Relationship Study. Tetrahedron 2014, 70, 6337-6351.

(34) Thiery, S.; Tondelier, D.; Declairieux, C.; Geffroy, B.; Jeannin, O.; Metivier, R.; RaultBerthelot, J.; Poriel, C. 4-Pyridyl-9,9'-Spirobifluorenes as Host Materials for Green and SkyBlue Phosphorescent OLEDs. J. Phys. Chem. C 2015, 119, 5790-5805.

(35) Brooksby, P. A.; Downard A. J. Electrochemical and Atomic Force Microscopy Study of Carbon Surface Modification via Diazonium Reduction in Aqueous and Acetonitrile Solutions. Langmuir 2004, 20, 5038-5045.

(36) Bard, A. J., Mirkin, M. V., Eds. Scanning Electrochemical Microscopy; Marcel Dekker: New York, 2001.

(37) Cornut, R.; Lefrou, C. A Unified New Analytical Approximation for Negative Feedback Currents with a Microdisk SECM Tip. J. Electroanal. Chem. 2007, 608, 59-66. 
(38) Cornut, R.; Lefrou, C. New Analytical Approximation of Feedback Approach Curves with a Microdisk SECM Tip and Irreversible Kinetic Reaction at the Substrate. J. Electroanal. Chem. 2008, 621, 178-184.

(39) Wittstock G.; Asmus T.; Wilhelm T. Investigation of Ion-Bombarded Conducting Polymer Films by Scanning Electrochemical Microscopy (SECM). Fresenius' J. Anal. Chem. 2000, 367, 346-351.

(40) Santos, L. ; Mattiuzzi, A.; Jabin, I.; Vandencasteele, N.; Reniers, F.; Reinaud, O.; Hapiot, P.; Lhenry, S.; Leroux, Y.; Lagrost, C. One-Pot Electrografting of Mixed Monolayers with Controlled Composition. J. Phys. Chem. C 2014, 118, 15919-15928.

(41) Anariba, F.; DuVall, S. H.; McCreery, R. L. Mono- and Multilayer Formation by Diazonium Reduction on Carbon Surfaces Monitored with Atomic Force Microscopy “Scratching”. Anal. Chem. 2003, 75, 3837-3844.

(42) http://gwyddion.net/

(43) Frisch, M. J.; Trucks, G. W.; Schlegel, H. B.; Scuseria, G. E.; Robb, M. A.; Cheeseman, J. R.; Scalmani, G.; Barone, V.; Mennucci, B.; Petersson, G. A. et al. Gaussian 09, Revision B.1; Gaussian, Inc.: Wallingford CT, 2009.

(44) Poriel, C.; Rault-Berthelot, J.; Thirion, D. Modulation of the Electronic Properties of $3 \pi-$ 2spiro Compounds Derived from Bridged Oligophenylenes: A Structure-Property Relationship. J. Org. Chem. 2013, 73, 886-898. 
(45) Poriel, C.; Liang, J.-J.; Rault-Berthelot, J.; Barrière, F.; Cocherel, N.; Slawin, A. M. Z.; Horhant, D.; Virboul, M.; Alcaraz, G.; Audebrand, N. et al. Dispirofluorene-Indenofluorene Derivatives as New Building Blocks for Blue Organic Electroluminescent Devices and Electroactive Polymers. Chem. Eur. J. 2007, 13, 10055-10069.

(46) Lagrost, C.; Leroux, Y.; Hapiot, P. Localized Electrochemistry for Studying Functional Carbon Surfaces. Electroanalysis 2016, 28, 2680-2687.

(47) Bard, A. J.; Fan, F. R. F.; Kwak, J.; Lev, O. Scanning Electrochemical Microscopy. Introduction and Principles. Anal. Chem. 1989, 61 (2), 132-138.

(48) Kwak, J.; Bard, A. J. Scanning Electrochemical Microscopy. Theory of the Feedback Mode. Anal. Chem. 1989, 61 (11), 1221-1227.

(49) DuVall, S. H.; McCreery, R. L. Control of Catechol and Hydroquinone Electron-Transfer Kinetics on Native and Modified Glassy Carbon Electrodes. Anal. Chem. 1999, 71, 4594-4602.

(50) Lhenry, S.; Leroux, Y. R.; Hapiot, P. Use of Catechol as Selective Redox Mediator in Scanning Electrochemical Microscopy Investigations. Anal. Chem. 2012, 84, 7518-7524.

(51) https://www.scm.com/

TOC graphic 
